\title{
Small mammal assemblage in beaver-modified habitats
}

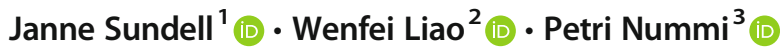 \\ Received: 21 July 2020 / Accepted: 28 October 2020 / Published online: 4 November 2020 \\ (C) The Author(s) 2020
}

\begin{abstract}
One of the less studied positive interactions among organisms is facilitation. Facilitation may have significant impact on diversity of species especially in low productive environments. We studied the effects of well-known facilitator and ecosystem engineer, the North American beaver (Castor canadensis), on small mammal assemblages in the boreal zone. The small mammals, namely voles, mice, and shrews, were trapped over 2 years in ten beaver-modified habitats and in ten control sites. Contrary to our expectations, we did not observe any differences between species or individual numbers between beaver-modified and control sites. However, there were differences in species composition between sites; grass-eating field voles (Microtus agrestis) and invertebrate-eating shrews (Sorex araneus, Neomys fodiens) tended to be more common in beaver sites while forest-dwelling wood lemmings (Myopus schisticolor) and yellow-necked mice (Apodemus flavicollis) were only captured in control sites. The most common species in both habitats was the bank vole (Myodes glareolus), which is a generalist in its habitat requirements. The bank vole's population structures were similar between the two habitat types. The actions of beavers in water bodies within boreal forests seem to have no effect on the small mammal diversity and their numbers at the regional scale but may have positive effect on them at the larger landscape level as beavers are increasing the overall habitat diversity in the landscape.
\end{abstract}

Keywords Biodiversity $\cdot$ Castor $\cdot$ Ecosystem engineer $\cdot$ Facilitation $\cdot$ Wetland

\section{Introduction}

Species interactions are important in determining the local species composition. Both negative and positive interactions are involved. While negative interactions, such as predation and competition, are more commonly investigated, positive ones can be equally essential in structuring communities (Bruno et al. 2003). One form of positive relationships is facilitation. Actions or just presence of a facilitator allows other

Communicated by: Jan M. Wójcik

Supplementary Information The online version contains supplementary material available at https://doi.org/10.1007/s13364-02000545-4.

Janne Sundell

janne.sundell@helsinki.fi

1 Lammi Biological Station, University of Helsinki, Pääjärventie 320, FI-16900 Lammi, Finland

2 Faculty of Biological and Environmental Sciences, University of Helsinki, P.O. Box 65, FI-00014 Helsinki, Finland

3 Department of Forestry, University of Helsinki, P.O. Box 27, FI-00014 Helsinki, Finland species to thrive. A common way of a facilitator to facilitate other species is modification of otherwise unsuitable abiotic and/or biotic environment so that it will become suitable for others to thrive (Stachowicz 2001). This is evident in many successional colonisation events where previous settlers modify habitat to be suitable for followers (e.g. Gallagher et al. 1983; Harris et al. 1984; Vieira et al. 1994). The effects of facilitation are expected to be significant in low productive environments (Wright and Jones 2004).

Especially influential are species, which are very abundant or otherwise have large effect on their living environment. These species are often called keystone species, keystone modifiers, or ecosystem engineers (Mills et al. 1993). One of the most well-known modifiers of habitat and related communities in boreal low productive settings are beavers, Castor spp. (Wright et al. 2002). They do often extensive changes in abiotic and biotic environments by building dams and that way increasing the water level and creating vast shallow water areas. They also cut down even large trees and left unwanted tree species to stand and die (Nummi and Kuuluvainen 2013). In the low productive areas, for example in the boreal zone, beavers clearly increase the productivity of the environment (Nummi and Holopainen 2014). 
Beaver effects on other species have been studied extensively from plants, invertebrates, fish, and amphibians to birds (reviewed by Stringer and Gaywood 2016). Most of the observed effects have been positive. However, apart from bats and otters, studies of beaver effects on other mammals are rare or rather anecdotal (Rosell et al. 2005; LeBlanc et al. 2007; Nummi et al. 2011; Stringer and Gaywood 2016).

We have recently studied the effect of beavers on terrestrial and semi-aquatic mammals (Nummi et al. 2019). However, the methods (snow tracking and camera trapping) used in that study were not effective in detecting small mammals (i.e. shrews, mice, and voles), although we found an indication that small mammals, as a group, seemed to be more common in beaver-modified habitats than in adjacent control habitats during winter based on the snow tracks.

The aim of this study was to investigate small mammal assemblages (namely voles, mice, and shrews) in beavermodified habitats. We expected that the species diversity and their numbers would be higher in beaver-modified habitat compared to control wetland habitat, because of known diversity increase in various trophic levels (plants, invertebrates, and vertebrates) should be reflected in species using them as food. Also, the shallow wetland area with habitat-specific vegetation would attract species associated to mesic environments such as water shrews, water voles, and field voles but maintain also forest-dwelling species. We also studied the quality of individuals within species to see whether there are differences between habitats in sex ratio, body mass, body condition, maturity status, or age. We expected to see more dominant individuals (older, larger, mature, and in good condition) in beaver habitats than in controls as beaver-modified habitats are assumed to be better and therefore favoured by dominant individuals.

\section{Materials and methods}

The study was conducted in Evo forested area in southern Finland $\left(61^{\circ} 10^{\prime} \mathrm{N}, 25^{\circ} 05^{\prime} \mathrm{E}\right)$. This boreal catchment of $66.5 \mathrm{~km}^{2}$ has tens of small lakes and ponds. The beavers originally living in the area were hunted to extinction in the end of 1500s and were later, in 1930s, reintroduced. Both the European (Castor fiber) and North American (C. canadensis) beavers were released into the area but currently only the latter exists (Lahti and Helminen 1974). The lakes of the area are typically small with relatively steep shoreline compared to beaver-modified ponds. Sparse emergent vegetation is mainly consisting sedges (Carex spp.) and common reed (Phragmites australis) and the narrow belt of floating vegetation is dominated by water lilies (Nuphar lutea and Nymphaea candida). Lakes are also lined with narrow strips of deciduous trees such as willows (Salix spp.), birches (Betula spp.), and alders (Alnus spp.). Otherwise, forests are dominated by coniferous
Scots pine (Pinus sylvestris) and Norway spruce (Picea abies; Nummi and Hahtola 2008).

For this study, we selected ten beaver-modified ponds. In those, beavers have been building a dam in the river or pond outlet and that way raised the water level and created extensive shallow water areas. Two of the sites were recently abandoned (2-3 years ago) and water level has lowered. The rest has been under flood for 3-34 years. Ten control sites were small lakes in the same drainage basin but were never altered by beavers (six sites) or abandoned 6-12 years ago (four sites). In the previous study (Nummi et al. 2019), no difference in mammal fauna was detected between these same sites that were never altered by beavers and those that were abandoned a long time ago.

We studied the small mammal assemblages by snaptrapping the beaver and non-beaver areas seven times in 2017-2019 (October and November in 2017, May and June in 2018, and August, September, and November in 2019). In each location, 30 traps were set in two parallel lines along the shoreline so that the first line was about $2-5 \mathrm{~m}$ from the shore and the second line was 5-6 $\mathrm{m}$ from the first line. Distance between snap-traps in lines was $5 \mathrm{~m}$. All snap-traps in the second line were small metal mouse-traps, while the first line included also three larger rat-traps. Mouse-traps were baited with rye bread while rat-traps were baited with carrot. Rattraps were used, as the mouse-traps are too small to catch adult water voles (Arvicola amphibius). In each trapping occasion, traps were set for two nights and checked after each night. Therefore, the trapping effort was 60 trap-nights per site per occasion, 420 trap-nights per site, and altogether 8400 trapnights. The overall small mammal abundance in our study area was estimated by biannual monitoring (May and September) using the small quadrat method $(15 \mathrm{~m} \times 15 \mathrm{~m}$ quadrat, three metal snap-traps in each corner, set for two nights; Myllymäki et al. 1971) resulting in 240 trap-nights per occasion. Monitoring in mainly forested areas yielded the following small mammal abundance indices during the study period: fall 2017 , 4.6; spring 2018, 0.4; fall 2018, 11.7; spring 2019, 3.8; and fall 2019, 12.5 ind./100 trapnights. Always more than $90 \%$ of captured small mammals were bank voles (Myodes glareolus).

\section{Statistical analysis}

We analysed the data in R software, version 3.6.1 (R Core Team 2019). We compared the species richness and the abundance per trapping occasion (60 trap-nights) in beaver and non-beaver patches. As our observations were possibly nested within patches, we used the 20 patches as random effects. The most common species in our catch (bank voles and field voles, Microtus agrestis) were also subjected to analyses of sex, maturity status, body mass (without intestines), body condition (body mass index (BMI): weight without intestines/snout 
to anus length ${ }^{2}$ ), and age (latter two only for bank voles) between the beaver and non-beaver patches. For age determination of bank voles, we used the ratio of root length and entire length in the upper second molars (Viitala 1971). We applied generalised linear mixed models (GLMM) to do the comparison; when GLMM could not handle the large numbers of zeros in our data, we applied zero-inflated models (Zuur and Ieno 2016). We applied all the models with R package "glmmTMB" (Brooks et al. 2017). The full models are described in Supplementary material Appendices 1, 2, and 3.

\section{Results}

In total, we trapped 215 individuals (2.56 ind./100 trap-nights) of eight species: bank voles, field voles, common shrews (Sorex araneus), Eurasian water shrews (Neomys fodiens), water voles, least weasels (Mustela nivalis), wood lemmings (Myopus schisticolor), and yellow-necked mice (Apodemus flavicollis). We found six small mammal species with 114 individuals trapped in beaver sites and seven species with 101 individuals by non-beaver sites (Fig. 1, Table 1). The least weasel was only trapped in the beaver site, while wood lemmings and yellow-necked mice were only trapped in nonbeaver sites. Additionally, water shrews and common shrews were more often captured in beaver than control sites but the number of individuals was too low for statistical testing. Our results showed that there was no difference in species richness $(p=0.454)$ nor abundance between the two types of habitat $(p$ $=0.539$, Tables $\mathrm{S} 1$ and S2). Bank voles and field voles were
Table 1 Total number of small mammal individuals and number of individuals per trapping occasion (60 trap-nights) in the beaver and non-beaver sites

\begin{tabular}{llllll}
\hline & \multicolumn{2}{l}{ Beaver sites } & & \multicolumn{2}{l}{ Non-beaver sites } \\
\cline { 2 - 3 } \cline { 5 - 6 } & Total & Per trapping & & Total & Per trapping \\
\hline Species richness & 6 & $0.87 \pm 0.92$ & 7 & $0.76 \pm 0.75$ \\
Abundance & 114 & $1.63 \pm 1.88$ & & 101 & $1.44 \pm 1.77$ \\
Bank vole & 71 & $1.01 \pm 1.41$ & 79 & $1.17 \pm 1.36$ \\
Field vole & 31 & $0.41 \pm 1.01$ & 13 & $0.17 \pm 0.64$ \\
Common shrew & 6 & - & 2 & - \\
Water shrew & 4 & - & 2 & - \\
Water vole & 1 & - & 1 & - \\
Least weasel & 1 & - & 0 & - \\
Wood lemmings & 0 & - & 2 & - \\
Yellow-necked mouse & 0 & - & 2 & - \\
\hline
\end{tabular}

the most abundant small mammals captured in our traps, but neither species differed in their abundance between beaver and non-beaver sites (Tables S3 and S4).

In bank voles, males were more frequently trapped than females (Table 2), but the individuals of neither males ( $p=$ $0.346)$ nor females $(p=0.913)$ had significant difference between beaver and non-beaver sites. Trapped immature bank voles had higher abundance than mature bank voles in both beaver and non-beaver sites, but no significant difference was found between the two types of habitats ( $p=0.605$ in immature bank voles, and 0.632 in mature bank voles). No

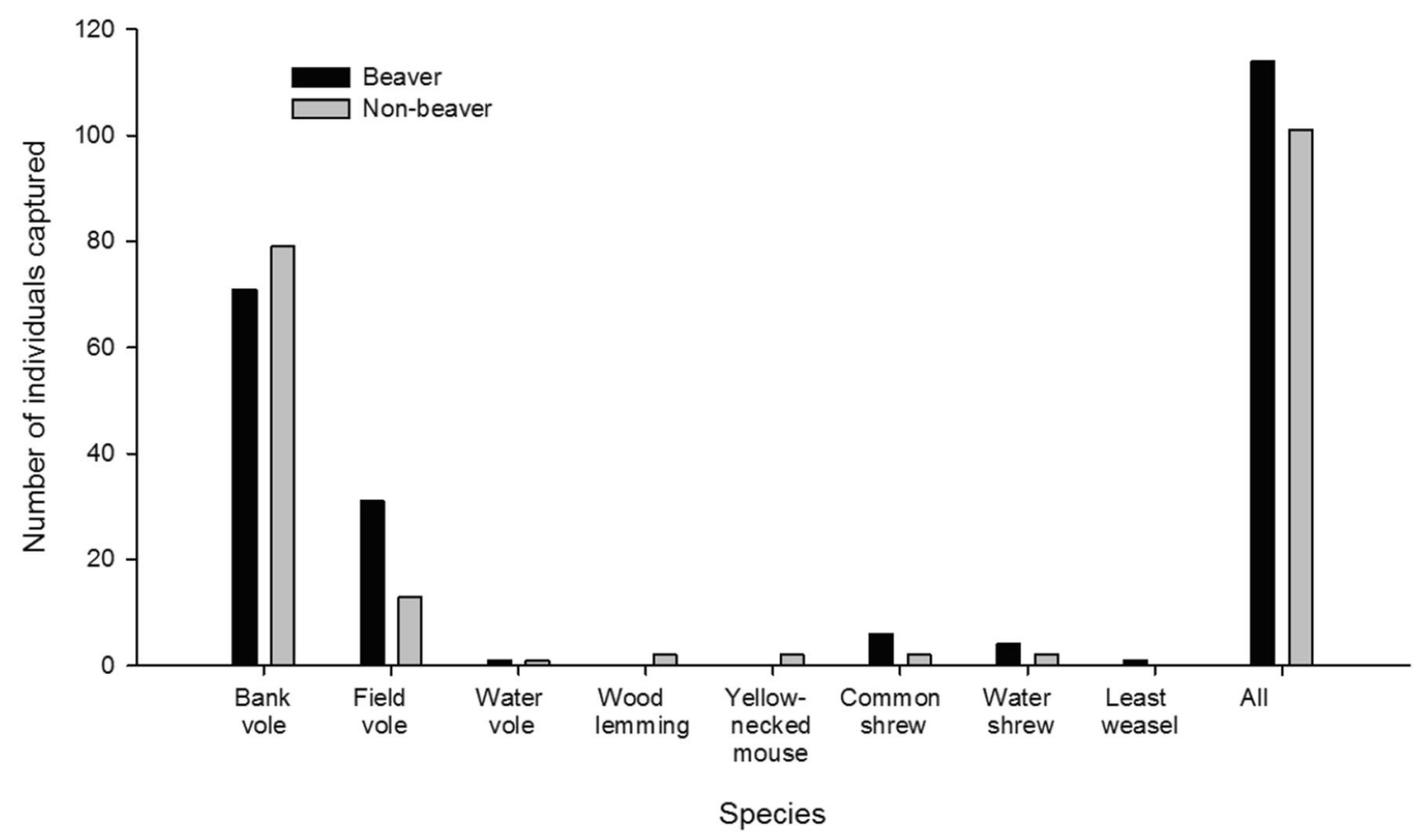

Fig. 1 Accumulated number of captured species in beaver and non-beaver sites 
Table 2 Bank voles in beaver and non-beaver sites. Some observations lack individual maturity information and they were excluded from the analysis. No significant differences were found between beaver and non-beaver sites

\begin{tabular}{llll}
\hline Categories & Beaver sites & Non-beaver sites & $p$ value \\
\hline Male & $0.73 \pm 1.31$ & $0.89 \pm 1.06$ & 0.346 \\
Female & $0.29 \pm 0.59$ & $0.29 \pm 0.66$ & 0.913 \\
Mature & $0.33 \pm 0.79$ & $0.37 \pm 0.68$ & 0.632 \\
Immature & $0.71 \pm 1.13$ & $0.59 \pm 1.03$ & 0.605 \\
Age structure (month old) & $3.79 \pm 3.38$ & $3.23 \pm 3.20$ & 0.502 \\
Body mass (g) & $19.93 \pm 4.37$ & $18.24 \pm 4.74$ & 0.994 \\
Body condition, BMI & $0.17 \pm 0.03$ & $0.16 \pm 0.02$ & 0.070 \\
\hline
\end{tabular}

significances were found between beaver and non-beaver sites in bank vole age structure $(p=0.502)$, body mass $(p=0.994)$ nor body condition ( $p=0.070$, Table 2$)$.

Field voles were more abundant in beaver than non-beaver sites (Table 1), although no significant difference was found in their occurrence ( $p=0.124)$ nor abundance ( $p=0.816$, Table S4). Male field voles tend to be more common in beaver than non-beaver sites ( $p=0.057$, Table 3$)$, while the abundance of females was too low to test. Mature and immature field voles had higher abundance per trapping in beaver than in non-beaver sites (Table 3 ) but without significance between the two types of habitats $(p=0.233$ in mature field voles, and 0.067 in immature bank voles). No difference was detected in body mass neither $(p=0.849)$.

\section{Discussion}

Against our predictions, we did not detect difference in species numbers or number of individuals between beaver-modified habitats and non-beaver habitats. However, species composition was somewhat different. Only yellow-necked mice and wood lemmings captured in this study were captured in non-beavermodified habitats. These species are clearly forest-dwelling

Table 3 Field voles in beaver and non-beaver sites. The numbers of female field voles were not tested due to insufficient data with only three individuals in beaver and two in non-beaver sites. No significance was found between beaver and non-beaver sites

\begin{tabular}{llll}
\hline Categories & Beaver sites & Non-beaver sites & $p$ value \\
\hline Male & $0.37 \pm 0.87$ & $0.14 \pm 0.62$ & 0.057 \\
Female & $0.04 \pm 0.26$ & $0.03 \pm 0.17$ & - \\
Mature & $0.25 \pm 0.69$ & $0.13 \pm 0.56$ & 0.233 \\
Immature & $0.17 \pm 0.54$ & $0.06 \pm 0.23$ & 0.067 \\
Body mass $(\mathrm{g})$ & $26.97 \pm 10.89$ & $27.60 \pm 8.18$ & 0.849 \\
\hline
\end{tabular}

species and are not likely to benefit anyway from the habitat modifications of beavers, although any strong conclusions cannot be made, as they were so rare in our catch. Especially the wood lemming is a habitat specialist found usually only in mature old-growth forests (Eskelinen 2002). Typically, in beavermodified habitats, the shore effect with less trees and more grasses and sedges is extended with expense of typical forest habitat, which can explain why these forest-dependent species were absent in the beaver habitats (Hyvönen and Nummi 2011). The bank vole is also a forest-dwelling species but more generalist in its habitat demands. However, it is often found in open grass-dominated habitats if its main competitor there, the field vole, is absent or rare (Sundell et al. 2012). Terwilliger and Pastor (1999) found that in North America, the red backed vole (Myodes gapperi), ecologically very similar species than the bank vole, was more common in surrounding forest habitats than beaver-modified habitat (i.e. beaver meadows). Although, the beaver-modified habitat is generally not favoured by the bank voles, they have often been found in beaver lodges (Ulevičius and Janulaitis 2007; Samas and Ulevičius 2015).

Generally, field voles are not common in forest-dominated landscapes such as our study area in Evo. Still, the field vole was the second most common species in our study. They, especially the males, tended to be more common in beavermodified habitats as expected, likely because their diet contains mainly grasses and other graminoids (Hansson and Larsson 1978), which plant groups are more abundant in beaver-modified habitats (Wright et al. 2002). However, even if there were almost twice as many field voles in beaver habitats compared to non-beaver habitats, the difference was not statistically significant due to high variance. Furthermore, field voles were captured in eight out of ten beaver habitats compared to five in non-beaver sites. Samas and Ulevičius (2015) similarly observed field voles to be more common in beaver lodges than control sites in nearby forest.

The only least weasel caught was captured from the beaver site. Even if it might be only coincidence that the only weasel was caught in the beaver habitat, it could be also due to the presence of field voles. In our earlier study (Nummi et al. 2019), we found more weasel tracks in beaver habitats in winter which supports this idea. Also, the capture of this only weasel happened in the site where at the same trapping session we captured several field voles. It has been suggested that especially during the breeding season of weasels, the field vole is an especially attractive prey for the least weasels because it is a larger and clumsier species than, for example, the bank vole, and also forms dense matrilinear aggregations (Henttonen 1987; Pusenius and Viitala 1993). Based on that, it is only expected that the only weasel was found in beaver habitat housing generally more field voles.

The other species that were captured more often in beaver sites than controls were the common shrew (six individuals in beaver sites vs two in control sites) and the water shrew (four vs two). 
Both were so rare in the catch that the difference could not be verified with statistical tests. However, both species were expected to be more common in beaver sites as the beaver-modified habitats are known to be more rich in invertebrates than nonbeaver habitats (Nummi et al. 2011; Bush and Wissinger 2016), and both species' diets are based mainly on invertebrates (Churchfield 1982, 1985). The water shrew is also eating amphibians, which are more numerous in beaver impoundments than non-beaver wetlands (Vehkaoja and Nummi 2015). The common shrew is a generalist in its habitat requirements (Sundell et al. 2012) and eats mainly terrestrial invertebrates (Churchfield 1982), but is likely to benefit also from insects emerging from shallow water and resting in the shoreline. In Latvia, common shrews were clearly more common in beaver lodges than in the forest surroundings (Samas and Ulevičius 2015)

There are only few other community-level studies focusing on the diversity of species and abundance of individuals of small mammals in beaver-modified habitats. The study by Medin and Clary (1991) conducted in ID, USA, similarly did not detect any difference in species richness between beaver-modified and nonbeaver habitat, but they found that the number of individuals in beaver habitat was thrice the number in the control area. The main difference was due to high number of the montane voles, Microtus montanus, and shrews (Sorex spp.). The montane vole is like the field vole in Eurasia, both preferring grassy moist habitats common in a beaver-modified environment (Murie 1971; Henttonen and Hansson 1984).

Although statistical difference was not found in the numbers of species or individuals, we wanted to study if there are still differences in the population structure of the most common species in our catch, the bank vole and the field vole. We expected that the presumably better habitat, the beavermodified sites, was occupied by the dominant individuals which are larger, older, mature, and/or in better condition, while subdominant individuals have to live in worse habitat (i.e. non-beaver habitat). Contrary to our expectations, we did not found other difference than that the field vole males tended to be more abundant in beaver-modified habitats than controls. We do not have a clear explanation for this but partial answer might be related to the fact that males are moving more than females, and especially young immature males are likely to be the functional group of the population finding first the new habitats (e.g. Myllymäki 1977). Beaver habitats have become available later than the control sites. The higher movement rate can also explain why more bank vole males were captured compared to females.

Our aim was not to obtain absolute differences between the numbers of species, as no single method can capture different species with the same efficiency. However, the metal snap-trap is a good compromise, as it is relatively efficient for most of the small mammal species present in our study area (e.g. Myllymäki et al. 1971; Korpimäki 1986). Despite modest differences in efficiencies between capture rates of species, the same method with the same intensity was applied in both habitats at the same times making habitat comparisons still valid. Removal trapping, such as ours, might have effect on the species assemblages in subsequent trappings, especially if densities are low, interval between trapping is short, and trapping effort is extensive. However, in our case, the density varied during the study but the trapping effort was not especially intensive: only two nights in relatively small area compared to available similar habitat, which might act as a source. A previous study (Christensen and Hörnfeldt 2003) has also showed that frequently sampled points had similar vole densities than pristine sites. Although previous trappings may have affected the results of the following trappings in our study, the effect can be assumed to be the same in beaver sites and controls.

Even if we did not detect any difference in small mammal species numbers or general abundance of individuals between beaver-modified habitats and non-beaver-modified wetlands at the regional level, the species composition tended to be different, which may indicate that the actions of the beaver as an ecosystem engineer may facilitate the richness of small mammal assemblages at the larger landscape scale. The beaver actions create a mosaic of habitats within boreal forests, which are in different successional stages from non-modified sites to flooded and different aged abandoned sites (Kivinen et al. 2020). This increase in habitat diversity is likely to affect also associated fauna and flora, and therefore it would be especially important to investigate the landscapes with and without beaver impact in order to have an answer to this question of conservation importance.

Acknowledgements We thank Steven Lexmond, Erminia Scarpulla, Ophelie Huet, Markus Wittstamm, Alina Posdziech, and Marvin Brandjes for assisting in the fieldwork.

Authors' contributions JS and PN designed the study and supervised the fieldwork. WL did the statistical analyses. JS led the writing and all authors contributed to the final manuscript.

Funding Open access funding provided by University of Helsinki including Helsinki University Central Hospital. The study was funded by Lammi Biological Station.

Data availability The data that support the findings of this study are available from the corresponding authors upon reasonable request.

\section{Compliance with ethical standards}

Conflict of interest The authors declare that they have no conflict of interest.

Ethics approval Small mammal trappings were conducted with the permissions MH 1776/2016/6.6.02 (Metsähallitus) and HAMELY/29/2017, LUO/21A/2017 (Häme Centre for Economic Development, Transport and the Environment).

Consent to participate Not applicable 
Consent for publication Not applicable

\section{Code availability Not applicable}

Open Access This article is licensed under a Creative Commons Attribution 4.0 International License, which permits use, sharing, adaptation, distribution and reproduction in any medium or format, as long as you give appropriate credit to the original author(s) and the source, provide a link to the Creative Commons licence, and indicate if changes were made. The images or other third party material in this article are included in the article's Creative Commons licence, unless indicated otherwise in a credit line to the material. If material is not included in the article's Creative Commons licence and your intended use is not permitted by statutory regulation or exceeds the permitted use, you will need to obtain permission directly from the copyright holder. To view a copy of this licence, visit http://creativecommons.org/licenses/by/4.0/.

\section{References}

Brooks ME, Kristensen K, van Benthem KJ, Magnusson A, Berg CW, Nielsen A et al (2017) glmmTMB balances speed and flexibility among packages for zero-inflated generalized linear mixed modeling. R J 9:378-400

Bruno JF, Stachowicz JJ, Bertness MD (2003) Inclusion of facilitation into ecological theory. Trends Ecol Evol 18:119-125

Bush BM, Wissinger SA (2016) Invertebrates in beaver-created wetlands and ponds. In: Batzer D, Boix D (eds) Invertebrates in freshwater wetlands. Springer, Cham, pp 411-449

Christensen P, Hörnfeldt B (2003) Long-term decline of vole populations in northern Sweden: a test of the destructive sampling hypothesis. J Mammal 84:1292-1299

Churchfield S (1982) Food availability and the diet of the common shrew, Sorex araneus, in Britain. J Anim Ecol 51:15-28

Churchfield S (1985) The feeding ecology of the European water shrew. Mammal Rev 15:13-21

Eskelinen O (2002) Diet of the wood lemming Myopus schisticolor. Ann Zool Fenn 39:49-57

Gallagher ED, Jumars PA, Trueblood DD (1983) Facilitation of softbottom benthic succession by tube builders. Ecology 64:1200-1216

Hansson L, Larsson TB (1978) Vole diet on experimentally managed reforestation areas in northern Sweden. Ecography 1:16-26

Harris LG, Ebeling AW, Laur DR, Rowley RJ (1984) Community recovery after storm damage: a case of facilitation in primary succession. Science 224:1336-1338

Henttonen H (1987) The impact of spacing behaviour in microtine rodents on the dynamics of the least weasel - a hypothesis. Oikos 50:366-370

Henttonen H, Hansson L (1984) Interspecific relations between small rodents in European boreal and subarctic environments. Acta Zool Fenn 172:61-65

Hyvönen T, Nummi P (2011) Plant succession in beaver patches during and after flooding. In: Sjöberg G, Ball JB (eds) Restoring the European beaver: 50 years of experience. Pensoft, Sofia, pp 163-171

Kivinen S, Nummi P, Kumpula T (2020) Beaver-induced spatiotemporal patch dynamics affect landscape-level environmental heterogeneity. Environ Res Lett 15:094065

Korpimäki E (1986) Predation causing synchronous decline phases in microtine and shrew populations in western Finland. Oikos 46:124-127

Lahti S, Helminen M (1974) The beaver Castor fiber (L.) and Castor canadensis (Kuhl) in Finland. Acta Theriol 19:177-189

LeBlanc FA, Gallant D, Vasseur L, Léger L (2007) Unequal summer use of beaver ponds by river otters: influence of beaver activity, pond size, and vegetation cover. Can J Zool 85:774-782
Medin DE, Clary WP (1991) Small mammals of a beaver pond ecosystem and adjacent riparian habitat in Idaho. US Department of Agriculture, Forest Service, Intermountain Research Station. Vol. 445

Mills LS, Soulé ME, Doak DF (1993) The keystone-species concept in ecology and conservation. BioScience 43:219-224

Murie JO (1971) Behavioral relationships between two sympatric voles (Microtus): relevance to habitat segregation. J Mammal 52:181-186

Myllymäki A (1977) Intraspecific competition and home range dynamics in the field vole Microtus agrestis. Oikos 29:553-569

Myllymäki A, Paasikallio A, Pankakoski E, Kanervo V (1971) Removal experiments on small quadrats as a means of rapid assessment of the abundance of small mammals. Ann Zool Fenn 8:177-185

Nummi P, Hahtola A (2008) The beaver as an ecosystem engineer facilitates teal breeding. Ecography 31:519-524

Nummi P, Holopainen S (2014) Whole-community facilitation by beaver: ecosystem engineer increases waterbird diversity. Aquat Conserv 24:623-633

Nummi P, Kuuluvainen T (2013) Forest disturbance by an ecosystem engineer: beaver in boreal forest landscapes. Boreal Environ Res 18(Suppl. A):13-24

Nummi P, Kattainen S, Ulander P et al (2011) Bats benefit from beavers: a facilitative link between aquatic and terrestrial food webs. Biodivers Conserv 20:851-859

Nummi P, Liao W, Huet O, Scarpulla E, Sundell J (2019) The beaver facilitates species richness and abundance of terrestrial and semiaquatic mammals. Glob Ecol Conserv 20:e00701

Pusenius J, Viitala J (1993) Varying spacing behaviour of breeding field voles, Microtus agrestis. Ann Zool Fenn 30:143-152

R Core Team (2019) R: a language and environment for statistical computing. R Foundation for Statistical Computing, Vienna, Austria. https://www.R-project.org/. Accessed 17 Apr 2020

Rosell F, Bozser O, Collen P, Parker H (2005) Ecological impact of beavers Castor fiber and Castor canadensis and their ability to modify ecosystems. Mammal Rev 35:248-276

Samas A, Ulevičius A (2015) Eurasian beaver building activity favours small mammals common for the forest. Balt For 21:244-252

Stachowicz JJ (2001) Mutualism, facilitation, and the structure of ecological communities. BioScience 51:235-246

Stringer AP, Gaywood MJ (2016) The impacts of beavers Castor spp. on biodiversity and the ecological basis for their reintroduction to Scotland, UK. Mammal Rev 46:270-283

Sundell J, Church C, Ovaskainen O (2012) Spatio-temporal patterns of habitat use in voles and shrews modified by density, season and predators. J Anim Ecol 81:747-755

Terwilliger J, Pastor J (1999) Small mammals, ectomycorrhizae, and conifer succession in beaver meadows. Oikos 85:83-94

Ulevičius A, Janulaitis M (2007) Abundance and species diversity of small mammals on beaver lodges. Ekologija 53:38-43

Vehkaoja MC, Nummi P (2015) Beaver facilitation in the conservation of boreal anuran communities. Herpetozoa 28:75-87

Vieira ICG, Uhl C, Nepstad D (1994) The role of the shrub Cordia multispicata Cham. as a 'succession facilitator' in an abandoned pasture, Paragominas, Amazonia. Vegetatio 115:91-99

Viitala J (1971) Age determination in Clethrionomys rufocanus (Sundevall). Ann Zool Fenn 8:63-67

Wright JP, Jones CG (2004) Predicting effects of ecosystem engineers on patch-scale species richness from primary productivity. Ecology 85: 2071-2081

Wright JP, Jones CG, Flecker AS (2002) An ecosystem engineer, the beaver, increases species richness at the landscape scale. Oecologia 132:96-101

Zuur AF, Ieno EN (2016) A protocol for conducting and presenting results of regression-type analyses. Methods Ecol Evol 7:636-645

Publisher's note Springer Nature remains neutral with regard to jurisdictional claims in published maps and institutional affiliations. 